
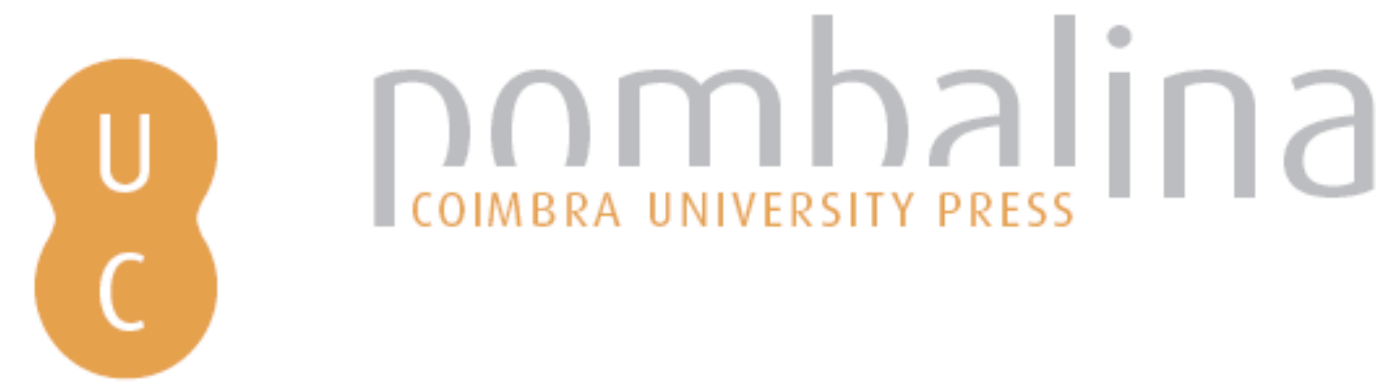

\title{
Infra-estruturas de dados espaciais nos municípios: contributo para a definição de um modelo de implementação
}
Autor(es):
Afonso, Clara; Julião, Rui Pedro
Publicado por: Imprensa da Universidade de Coimbra
URL
persistente:
URI:http://hdl.handle.net/10316.2/31148
DOI:
DOI:http://dx.doi.org/10.14195/978-989-26-0244-8_64
Accessed : $\quad$ 26-Apr-2023 09:12:48

A navegação consulta e descarregamento dos títulos inseridos nas Bibliotecas Digitais UC Digitalis, UC Pombalina e UC Impactum, pressupõem a aceitação plena e sem reservas dos Termos e Condições de Uso destas Bibliotecas Digitais, disponíveis em https://digitalis.uc.pt/pt-pt/termos.

Conforme exposto nos referidos Termos e Condições de Uso, o descarregamento de títulos de acesso restrito requer uma licença válida de autorização devendo o utilizador aceder ao(s) documento(s) a partir de um endereço de IP da instituição detentora da supramencionada licença.

Ao utilizador é apenas permitido o descarregamento para uso pessoal, pelo que o emprego do(s) título(s) descarregado(s) para outro fim, designadamente comercial, carece de autorização do respetivo autor ou editor da obra.

Na medida em que todas as obras da UC Digitalis se encontram protegidas pelo Código do Direito de Autor e Direitos Conexos e demais legislação aplicável, toda a cópia, parcial ou total, deste documento, nos casos em que é legalmente admitida, deverá conter ou fazer-se acompanhar por este aviso.

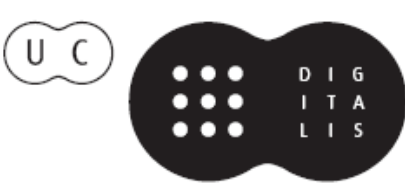




\section{TRUNFOS DE UMA}

\section{EOGRAFIA ACIVA}

\section{DESENVOLVIMENTO LOCAL,}

AMBIENTE,

ORDENAMENTO

E TECNOLOGIA

Norberto Santos

Lúcio Cunha

COORDENAÇÃO 
Clara Afonso ${ }^{1}$, Rui Pedro Julião ${ }^{2}$

${ }^{1}$ Município de Caminha

${ }^{2}$ e-GEO/UNL

\author{
INFRA-ESTRUTURAS DE DADOS ESPACIAIS NOS MUNICÍPIOS \\ CONTRIBUTO PARA A DEFINIÇÂO DE UM MODELO DE IMPLEMENTAÇÃO
}

\title{
1. INTRODUÇÃO
}

O presente artigo resulta da dissertaçáo de Mestrado em Ciência e Sistemas de Informação Geográfica, apresentada no Instituto Superior de Estatística e Gestão de Informação da Universidade Nova de Lisboa em Fevereiro de 2009.

Os objectivos traçados para a conduçáo do trabalho foram abrangentes, consistindo na definiçáo do estado da arte quanto ao desenvolvimento de IDE, como ponto de partida para a apresentaçáo da uma proposta de desenvolvimento de um projecto de âmbito local no Município de Caminha.

Do ponto de vista metodológico, o trabalho iniciou com uma reflexão preliminar para a formulação de objectivos gerais e do esboço da estrutura do trabalho, passando para uma fase mais sistemática, que compreendeu a realizaçáo de uma exaustiva e extensa pesquisa bibliográfica e metodológica, assim como a análise crítica de diversas IDE.

\section{A NATUREZA E O CONCEITO DE INFRA-ESTRUTURAS DE DADOS ESPACIAIS}

Ao tentar encontrar uma definição para IDE, a primeira dificuldade prende-se com o próprio termo a adoptar. No âmbito do presente trabalho adoptou-se o termo Infra-estrutura de Dados Espaciais, IDE na forma abreviada, equivalente ao termos inglês 'Spatial Data Infrastructure', SDI na forma abreviada, adoptado pela generalidade dos autores.

No que respeita à definição, uma das mais conhecidas é a apresentada por Bill Clinton em 1994, na 'Executive Order' 12906, segundo a qual a “'National Spatial Data Infrastructure' (NSDI) means the technology, policies, standards, and human resources necessary to acquire, process, store, distribute, and improve utilization of geospatial data" (Executive Order 12906, 1994).

As IDE funcionam, de um modo geral, numa base hierárquica. $\mathrm{O}$ seu desenvolvimento requer um conhecimento da natureza, conceito, componentes e impacte dos princípios globais (Rajabifard, 2002: p. 26). 


\section{AS INFRA-ESTRUTURAS DE DADOS ESPACIAIS ACTUAIS}

\subsection{A emergência das Infra-estruturas de Dados Espaciais}

Encontram-se actualmente em construção IDE nacionais, sub-nacionais ou supranacionais, cujos objectivos primordiais são, geralmente, (i) a promoção do desenvolvimento económico, (ii) o estímulo à melhor governação e (iii) a promoção do desenvolvimento sustentável (Masser, 2007: p. 17).

Masser (2007: p. 17) designa de 'fenómeno IDE' os acontecimentos neste domínio nos últimos cinquenta anos, tendo liderado o movimento países como a Austrália, o Canadá, a Holanda, Portugal e os Estados Unidos da América.

\subsection{A Directiva INSPIRE}

A iniciativa INSPIRE foi lançada em 2001 pela Comissão Europeia e desenvolvida em cooperaçáo com os Estados-Membros, os países em vias de adesão e grupos de interesse ao nível local e regional, com o envolvimento de um conjunto alargado de instituiçóes europeias, tendo como finalidade tornar possível a disponibilização da informação geográfica de modo a permitir uma análise do território como se não existissem fronteiras.

Esta iniciativa estabelece a criação de uma IDE para a Europa, obrigando os EstadosMembros a gerirem e disponibilizarem dados e serviços de informação geográfica, utilizável na formulação, implementação e avaliação das políticas ambientais da União Europeia, em conformidade com um conjunto de especificaçóes, garantindo assim a interoperabilidade.

O projecto tem um carácter legal, materializado na Directiva INSPIRE (Directiva 2007/2/CE do Parlamento Europeu e do Conselho, 2007), de 14 de Março, que entrou em vigor no dia 15 de Maio de 2007, sendo hoje uma incontornável referência mundial e um dos projectos mais ambiciosos no contexto de desenvolvimento de IDE em toda a Europa.

\subsection{O Sistema Nacional de Informação Geográfica}

O Sistema Nacional de Informação Geográfica (SNIG) é a IDE Nacional de Portugal, encontrando-se entre as onze iniciativas de primeira geração identificadas por Masser (1999: p. 68) e "tem por objectivo proporcionar, a partir dos vários pontos de acesso, a possibilidade de pesquisar, visualizar e explorar a informação geográfica sobre o território nacional" (IGP, 2007).

A coordenação e dinamização do SNIG é realizada pelo Instituto Geográfico Português (IGP). O elo de ligação entre parceiros é o geoportal, que se encontra estruturado em quatro secçôes: (i) catálogo; (ii) visualizador; (iii) aplicaçóes e (iv) geocomunidade (IGP, 2007).

No seio das perspectivas de desenvolvimento do SNIG e um dos principais desafios que hoje se colocam é o respeito pelas exigências da Directiva INSPIRE, sendo o IGP o ponto focal nacional coordenador. 


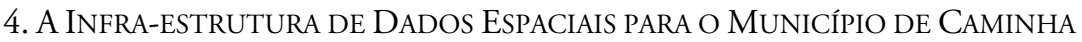

\subsection{O concelho de Caminha}

Caminha localiza-se no Noroeste de Portugal, sendo um dos 10 concelhos da NUT III - Minho-Lima, que corresponde ao distrito de Viana do Castelo.

Em termos de área, o concelho abrange cerca de $136,45 \mathrm{~km}^{2}$, distribuídos por 20 freguesias, com uma área média de $6,82 \mathrm{~km}^{2}$ (IGP, 2008), onde residem 17069 habitantes (INE, 2001).

\subsection{A estrutura e organização dos serviços do Município de Caminha}

O organigrama e regulamento interno do Município de Caminha foi publicado na íntegra pelo Aviso n. 22 701-A/2007, (2. ${ }^{a}$ série), de 19 de Novembro, no Diário da República.

A macroestrutura do Município de Caminha integra, de acordo com o documento enunciado, a Presidência, o Departamento de Gestão e Investimento (DGI), a Divisão de Obras Particulares, Planeamento e Gestão Urbanística (DOPPGU) e a Divisão Sócio-Cultural (DSC). Do DGI dependem três divisões, designadamente a Divisão Administrativa e Financeira (DAF), a Divisão de Obras Públicas e Serviço de Transportes (DOPST) e a Divisão de Abastecimento Público, Ambiente e Serviços Urbanos (DAPASU).

\subsection{Proposta de desenvolvimento de uma Infra-estrutura de Dados Espaciais}

\subsubsection{Fundamentação}

A adopção da Directiva INSPIRE veio introduzir uma nítida alteração na abordagem adoptada em relação à informação geográfica na Europa, onde vão emergindo iniciativas que constituem excelentes exemplos para o desenvolvido de novos projectos, sendo notoria a lacuna a nível local.

De acordo com Masser (2007: p. 80), os recursos humanos da administraçáo local estáo ainda pouco sensibilizados e possuem conhecimentos limitados quanto ao potencial e vantagens das IDE.

Porém, os órgãos da administração local são potencialmente os maiores utilizadores de Sistemas de Informação Geográfica (SIG), uma vez que a generalidade dos serviços que prestam possui uma dimensão espacial. É nesta perspectiva que se defende, tal como apresentado por Alfaro et al. (2007: p. 23), que o mundo das IDE é um complemento extraordinário do mundo SIG, pelo que devem ser observados e desenvolvidos de forma complementar.

Assim, considera-se pertinente avançar com a proposta de desenvolvimento de uma IDE L para o Município de Caminha, em articulaçáo com o SIG Municipal e tendo em conta as orientaçóes da Directiva INSPIRE.

A IDE L do Município de Caminha deverá assumir a forma de uma plataforma de troca e partilha de informação geográfica e conhecimento, através da Internet, na qual 
participem um conjunto alargado de parceiros do sector público, privado e académico, incluindo toda a comunidade em geral.

\subsubsection{Objectivos}

Os objectivos estratégicos, centrados numa visão global e nas metas de longo prazo da IDE L são: (i) impulsionar o crescimento económico; (ii) promover o desenvolvimento sustentável e (iii) contribuir para a modernização, eficiência e eficácia dos serviços.

Os objectivos operacionais, centrados em questóes de ordem prática e em eixos prioritários de intervenção da IDE L são: (i) dar coerência à informação geográfica; (ii) incrementar a cooperação externa na aquisição e gestão de informaçáo geográfica; (iii) evitar a duplicação de informação geográfica; (iv) disponibilizar informação geográfica; (v) participar em redes de partilha de experiências e conhecimentos em matéria de informação geográfica e (vi) integrar a rede de pontos focais INSPIRE.

\subsubsection{Princípios e componentes}

a) Estrutura institucional

A estrutura institucional, encarada como o enquadramento existente que regulamenta os órgãos da administração pública, é vital para suportar o arranque inicial e a futura sustentabilidade da IDE L. É importante distinguir, neste âmbito: (i) o nível europeu; (ii) o nível nacional e (iii) o nível local.

Neste contexto, merece destaque a Directiva 2007/2/CE do Parlamento Europeu e do Conselho, de 14 de Março de 2007, que estabelece uma infra-estrutura de informação geográfica na Comunidade Europeia (INSPIRE) e o Decreto-Lei n. ${ }^{\circ}$ 180/2009, de 7 de Agosto, que procede à revisão do Sistema Nacional de Informação Geográfica, transpondo para a Ordem Jurídica Interna a Directiva INSPIRE, fixando as normas gerais para a constituição de IDE em Portugal e criando o Registo Nacional de Dados Geográficos (RNDG).

A principal acçáo a empreender no âmbito da iniciativa proposta passa por rever a estrutura e organização dos serviços municipais, autonomizando uma unidade funcional responsável pelo SIG e pela IDE L.

b) Estrutura normativa

As normas, padróes e recomendaçôes são imprescindíveis no âmbito das IDE, permitindo que serviços, tecnologias e dados sejam coerentes, compatíveis e interoperáveis.

O trabalho de desenvolvimento da IDE L deverá ser realizado de acordo com a estrutura normativa existente, atendendo: (i) às normas internacionais da família 'Internacional Organization for Standardization' (ISO) 19100; (ii) aos padróes definidos pelo 'Open Geospatial Consortium' (OGC) e às (iii) recomendaçôes de interesse no âmbito da IDE L.

\section{c) Tecnologia}

Ao nível da tecnologia, a proposta de IDE L deverá desenvolve-se em cinco áreas principais: (i) tecnologia de armazenamento; (ii) tecnologia para processamento de informação geográfica; (iii) tecnologia para produção e gestão de metadados; (iv) tecnologia para o desenvolvimento de 'web services' e (v) tecnologia de visualizaçáo. 
d) Política de dados

No contexto da IDE L do Município de Caminha deve ser estabelecida uma política de dados coerente, materializada em regulamentos, protocolos e acordos de colaboração, necessários ao aumento da disponibilidade de dados espaciais e ao envolvimento dos principais parceiros do projecto.

As principais acçôes a realizar no âmbito da política de dados podem resumir-se nos seguintes pontos: (i) identificar os protocolos de informação geográfica existentes; (ii) identificar as possibilidades de protocolos para aumento da disponibilidade de informaçáo geográfica; (iii) criar regulamentos municipais para a aquisição, gestão e cedência de informação geográfica e (iv) identificar os técnicos e os gestores de informação geográfica.

e) Dados

Os dados são um elemento central, quer ao nível do desenvolvimento do SIG Municipal, quer da IDE L. A principal tarefa neste âmbito deverá consistir na identificação da informação geográfica necessária ao desenvolvimento da IDE L, que deverá englobar as seguintes acçóes: (i) realizar inquéritos de necessidades de dados espaciais; (ii) identificar os dados espaciais disponíveis; (iii) adquirir, produzir e gerir os dados espaciais necessários; (iv) disseminar e divulgar os dados espaciais disponíveis e (v) promover acçôes de esclarecimento sobre os dados espaciais com os parceiros.

\section{f) Metadados}

É essencial, no desenvolvimento da IDE L, ter em conta as normas da família ISO 19100 no que respeita aos metadados (19115, 19115-2 e 19139), o Perfil MIG, o suporte tecnológico, assim como o RNDG.

As principais acçôes a realizar neste âmbito podem resumir-se nos seguintes pontos: (i) produzir e gerir metadados; (ii) disseminar e divulgar os metadados; (iii) criar as figuras dos técnicos e do gestor municipal de metadados; (iv) promover acçôes de esclarecimento sobre metadados com os parceiros e (v) publicar os metadados no RNDG.

\section{g) Serviços}

Os principais serviços que devem ser desenvolvidos quanto às IDE são: (i) o Serviço de Mapas na Web (WMS); (ii) o Serviço de Entidades Geográficas na Web (WFS); (iii) o Serviço de Coberturas na Web (WCS); (iv) o Serviço de Roteiro (Gazetteer); (v) o Serviço de Catálogo na Web (CSW) e o (vi) Descritor de Estilos de Representação (SLD).

Deverá dar-se prioridade, pelas suas características, ao WMS, ao 'Gazetter' e ao CSW, estando assim a apontar-se como eixos prioritários: (i) a produçấo normalizada dos temas essenciais, a disponibilizar via WMS; (ii) a produção normalizada da toponímia, a disponibilizar via 'Gazetteer' e (iii) a produção e gestáo de metadados, a disponibilizar via CSW.

\section{h) Pessoas}

No desenvolvimento de uma IDE L devem ser claramente identificados os parceiros e utilizadores. Na proposta apresentada por Dias para o Município de Odivelas foram identificados cinco grupos (Dias, 2006: p. 96): (i) governo; (ii) ensino; (iii) mercado/ /empresa; (iv) cidadão e (v) outros intervenientes.

Tendo em conta que estamos perante o mesmo nível da administração, considera-se válida para o Município de Caminha a mesma abordagem. 


\subsubsection{Modelo conceptual}

A proposta de modelo conceptual para o caso em análise surge numa lógica de ajustamento à estrutura organizacional e à dinâmica preexistente, com as necessárias adaptaçóes inerentes ao desenvolvimento da IDE L.

Considera-se pertinente, neste sentido, que esteja prevista uma estrutura directiva, composta pelo executivo municipal, suportada por uma unidade de coordenaçáo claramente identificado no seio da organização, que poderá assumir a forma de um sector de informaçáo geográfica.

Deverá estar prevista a existência de um órgão consultivo no qual a direcção e a coordenação da IDE L possam apoiar-se, podendo ser assumido por parceiros do meio académico, por uma IDE hierarquicamente superior, ou ambas as hipóteses, numa perspectiva integrada.

Ao nível operacional devem considerar-se todos os componentes da IDE L, que deverão ser transversais a todo o trabalho que venha a ser desenvolvido. Contudo, para garantir a objectividade da infra-estrutura, o seu desenvolvimento deverá distribuir-se por grupos de trabalho que poderão respeitar a estrutura da organizaçáo, na perspectiva das divisóes. Para responder a questôes específicas deve prever-se a constituiçáo de grupos de trabalho na perspectiva de projecto.

\section{CONSIDERAÇÓES FINAIS}

Do contexto analisado acerca dos desafios que hoje se colocam ao desenvolvimento de uma IDE L, resultam as seguintes conclusóes gerais: (i) não existe uma definição universal de IDE, havendo variaçóes de acordo com o contexto de cada projecto ou autor, integrando diferentes princípios e componentes, embora todas as definiçóes apresentem pontos em comum; (ii) as diferentes IDE apresentam uma grande heterogeneidade, transparecendo a adaptação às condições intrínsecas do seu contexto, levando há conclusão de que não existe um modelo único a seguir; (iii) a Directiva INSPIRE veio introduzir, nos diferentes Estados-Membros, a estrutura normativa adequada ao desenvolvimento de IDE, estando reunidas as condiçóes para a emergência de projectos a diferentes níveis e (iv) nota-se em Portugal a ausência de um nível intermédio entre a administração local e a administração central, que constitua uma estrutura de suporte para os projectos locais.

Partindo destas conclusôes, tomou-se consciência de um conjunto de limitaçóes no que toca ao contexto de desenvolvimento de IDE, levando a apontar algumas recomendaçóes que será pertinente ter em consideração no desenvolvimento de futuros trabalhos neste domínio, designadamente: (i) a necessidade de desmistificação de conceitos e uma maior delimitação do âmbito das IDE e dos SIG; (ii) a necessidade de um maior aprofundamento quanto à natureza hierárquica das IDE, tendo em conta as relaçóes entre diferentes níveis e parceiros, assim como as diferentes áreas sectoriais envolvidas; (iii) a necessidade de definição de factores críticos de sucesso, que possam contribuir para a definição do Plano de Projecto; (iv) a necessidade de definiçáo de indicadores de monitorização; (v) a necessidade de se aperfeiçoarem as análises custo-benefício e (vi) a necessidade de abordagens mais aprofundadas no que respeita ao registo das bases de dados geográficas e aos direitos de autor e propriedade intelectual. 


\section{REFERÊNCIAS BIBLIOGRÁFICAS}

Alfaro, Alvaro Anguix; Muelas, Luis W. Sevilla e Rico, Gabriel Carrión 2007, 'gvSIG: un Cliente avanzado para las Infraestructuras de Datos Espaciales', Forum Geográfico', Revista Cientifica e Técnica do IGP, A Informação Geográfica e os desafios da gestão territorial e ambiental, Ano II, N. o 2, pp. 15-23.

Aviso n. 22 701-A/2007. D.R. n. ${ }^{\circ}$ 222, Suplemento, Série II de 2007-11-19 [Altera o quadro de pessoal da Câmara Municipal de Caminha], pp. 33592-(2) - 33592-(10).

Decreto-Lei n.o 180/2009. D.R. N.o 152, Série I de 2009-08-07 [Aprova o regime do Sistema Nacional de Informação Geográfica, transpondo para a ordem jurídica interna a Directiva n. ${ }^{\circ}$ 2007/2/CE, do Parlamento Europeu e do Conselho, de 14 de Março, que estabelece uma Infra-Estrutura de Informação Geográfica na Comunidade Europeia (INSPIRE), e revoga o Decreto-Lei n. ${ }^{o}$ 53/90, de 13 de Fevereiro], pp. 5132 - 5139.

Dias, Rui Manuel Pires 2006, Infra-estruturas Municipais de Dados Espaciais, Dissertação de Mestrado em Estatística e Gestão de Informação, Instituto Superior de Estatística e Gestão de Informação da Universidade Nova de Lisboa.

Directiva 2007/2/CE do Parlamento Europeu e do Conselho, de 14 de Março. Jornal Oficial da Uniáo Europeia, L 108 de 25.4.2007 [estabelece uma infra-estrutura de informação geográfica na Comunidade Europeia (INSPIRE)], pp. 1-14.

Executive Order 12906 of April 11, 1994. Federal Register Vol. 59, N. ${ }^{\circ}$ 71, 1993-04-13, [Coordinating Geographic Data Acquisition and Access: The National Spatial Data Infrastructure / Presidential Documents], 4 p.

IGP 2007, Página do SNIG, Sistema Nacional de Informação Geográfica, [Online] Available at: http://snig.igeo.pt/.

IGP 2008, Carta Administrativa Oficial de Portugal, CAOP 2008.0, [Limites Administrativos Oficiais (Limites de País, Limites de Distrito, Limites de Concelho e Limites de Freguesia)], Março de 2008, formato digital ArcView (SHP), [Online] Available at: http://www.igeo.pt/produtos/cadastro/caop/versao2008_0.htm.

INE 2001, Recenseamento Geral da População e da Habitação de 2001, [Online] Available at: http://www.ine.pt/.

Julião, Rui Pedro 2006, 'Sistema Nacional de Informação Geográfica', Actas ESIG 2006 - IX Encontro de Utilizadores de Informação Geográfica, Taguspark, Oeiras.

Julião, Rui Pedro; Silva, Henrique; Furtado, Danilo e Bonnet, Artur 2008, 'O Sistema Nacional de Informação Geográfica como contributo para a construção de um Infra-estrutura Europeia de Dados Espaciais', MappingRevista Internacional de Ciências de la Terra, N.o 126, pp. 62-65.

Masser, Ian 1999, 'All and sizes: the first generation of national spatial data infrastructures', International Journal of Geographic Information Science, Vol. 13, N.o 1, pp. 67-84.

Masser, Ian 2007, Building European Spatial Data Infrastructures. ESRI Press, Redland, California.

Rajabifard, Abbas 2002, Diffusion of Regional Spatial Data Infrastructures: with particular reference to Asia and the Pacific, Dissertação de Doutoramento, Departamento de Geomática da Faculdade de Engenharia da Universidade de Melbourne. 